\title{
The Army's War against Malaria: Collaboration in Drug Research during World War II
}

\author{
MARY ELLEN CONDON-RALL
}

$\mathbf{M}$ alaria battered allied forces in the early months of World War II. The disease produced one-half million American casualties and devastated friendly forces as well. By 30 January 1943, malaria had struck four times for every allied service member in the southwest Pacific, making control and treatment urgent priorities for the U.S. Army's medical establishment. ${ }^{1}$

Malaria is spread through bites from Anopheles mosquitoes infected with one of four species of Plasmodium. U.S. Army forces suffered several types of malaria, but Plasmodium vivax and Plasmodium falciparum were the most common. Cases of vivax malaria outnumbered those of falciparum malaria by 6.2 to 1 . Attacks of chills, fever, and sweating, every other day, which put men out of action for a week or longer, characterized both. Vivax debilitated its victims, making them liable to secondary infections that could prove fatal. The disease still was not generally a primary cause of death. Conversely, Falciparum malaria, if left untreated, could lead to death. The majority of troops sent into a malarial region came down with the disease in three to four weeks, some earlier. The most pressing problem for the U.S. Army was the development of a prophylactic drug or a malaria cure. ${ }^{2}$

During the second half of World War II, military and civilian scientists in the United States cooperated with each other and with allied

MARY ELLEN CONDON-RALL is a historian at the U.S. Army Center of Military History. She holds a Ph.D. from University College, University of London. She has published a number of articles on the British Navy and U.S. military medicine, and has co-authored the forthcoming The Medical Department: Medical Service in the War Against Japan, a volume in the Center of Military History's World War II series. She recently completed a study on host nation medical support during the war in the Persian Gulf. Address for correspondence: 3508 Beret Lane, Silver Spring, MD 20906. 
scientists to help the armed forces combat malaria. They worked through the Offices of the Surgeon General of the U.S. Army and the U.S. Navy, the National Research Council, the Board for the Coordination of Malarial Studies, the Office of Scientific Research and Development, the Australian Military Mission, and the British Medical Research Council, all in Washington, D.C. The Board for the Coordination of Malarial Studies, which the National Research Council established in November 1943 to guide research expansion and coordinate joint efforts, became the focal point for collaboration. These alliances produced hundreds of malaria studies and thousands of new compounds, some of which tested superior to traditional antimalarials. This cooperative effort improved chemotherapy for prevention and treatment after years of neglect in the development of antimalarial drugs.

This article focuses on the establishment of the Board for the Coordination of Malarial Studies, the development of new antimalarial drugs, and collaboration with allies on drug research. The latter produced special U.S.-Australia and U.S.-Britain relationships.

\section{Early Efforts to Combat Malaria}

Between World War I and World War II, the Malaria Commission of the League of Nations and the International Health Division of the Rockefeller Foundation undertook antimalarial campaigns, acquiring knowledge and skills that would later benefit the military. The Malaria Commission regarded drugs as the main line of defense against malaria, whereas the Rockefeller Foundation, which soon came to dominate malaria control, favored destroying the Anopheles mosquito, which transmitted the disease. The World War II program involved both approaches, but it soon became clear that an attempt to control malaria through the mosquito was probably hopeless during combat. Thus, the main attack on malaria had to come through drugs. ${ }^{3}$

War pushed the scientific community to create an organization to help the armed forces control malaria. At the request of the U.S. Army Medical Department, the National Research Council brought together eminent malariologists from the nation's finest institutes and laboratories to discuss research. The newly established Office of Scientific Research and Development, at the behest of its Committee on Medical Research, provided funds for the development of antimalarial drugs. The Committee on Medical Research worked closely with the National Research Council in evaluating research needs, assembling experts, choosing promising projects and coordinating studies to combat malaria. Both agencies worked 
through the British Scientific Mission and medical representatives in the Australian Military Mission in Washington D.C. to correlate malaria studies with allies. ${ }^{4}$

During the first half of the war, research focused on the search for better antimalarial drugs, investigations into atabrine, the German synthetic drug that became the preferred field prophylactic after the Japanese cut off the source of quinine (an alkaloid of cinchona bark), and improved regimens of malaria therapy and suppression. By the autumn of 1943 scientists had not found a better antimalarial drug, but they had proved that atabrine could prevent and cure falciparum malaria and was vastly superior to quinine. Clinical trials of atabrine had improved regimens of therapy and suppression, which the armed forces quickly adopted. The war had prompted the scientific community to obtain in a single year far more information about atabrine than had been published in the previous decade. $^{5}$

When no drugs, including atabrine, could cure vivax malaria, scientists intensified their search for a malaria cure. They also wanted to test atabrine in the field to determine its best use. Expansion in studies and increased testing required more personnel and facilities and a reorganization to better coordinate joint efforts. More participation on the part of the armed forces to include controlled field studies or studies within military hospitals would solve the first problem. The establishment of a board with military and civilian members to provide close correlation of military studies with civilian laboratories would solve the second.

\section{The Board for the Coordination of Malarial Studies}

In November 1943, Dr. Lewis H. Weed, an eminent anatomist from The Johns Hopkins University Medical School and chairman of the National Research Council's Division of Medical Sciences, set up the joint Board for the Coordination of Malarial Studies with equal representation from the Office of Scientific Research and Development, the Army, the Navy, the United States Public Health Service, and the National Research Council. At biweekly meetings, the board would facilitate the sharing of research and become a clearing house for reports from the field and the dissemination of information to scientists. The new board could counsel the Office of Scientific Research and Development on its research programs, while guiding the studies of the Army, the Navy, and the Public Health Service. $^{6}$ 
Panels on synthesis, pharmacology, clinical testing, and biochemistry of antimalarials that had been working with the National Research Council on drug research since January 1943 continued under the board. A fifth panel, the panel of review, was added. The panel of review met every two weeks to integrate the work of the four panels and to consider promising leads. In particular, the panel reviewed the screening data on all compounds, sought to guide the work of the synthetic chemists, and selected drugs that warranted clinical trials. ${ }^{7}$

When advances in chemotherapy warranted clinical testing (tests of antimalarial drugs on man with induced malaria in a controlled environment, such as a clinic), the Board for the Coordination of Malarial Studies recommended limited trials in accordance with protocols suggested by the board to installations at home and overseas. On the board's recommendations, scientists conducted field tests (on man in a malarious region without inducing malaria) of drugs that had passed the clinical trials. Scientists informed the board of their results through reports. This arrangement maintained liaison between the basic laboratory and the proving ground. ${ }^{8}$

\section{New Antimalarial Drugs}

Although research teams had proven that properly administered atabrine could suppress malaria and actually cure falciparum malaria, the Army and the other services were concerned about returning troops seeded with vivax malaria that atabrine could not cure. These troops would develop full-blown attacks as soon as they returned and stopped taking their daily doses of the antimalarial. Moreover, the attacks would probably continue from one to three years, because suppression did not influence the ultimate course of the disease. So it became necessary to continue the search for a cure that could destroy the parasites that produced vivax malaria. ${ }^{9}$

To that end, civilian research in the United States expanded in early 1944 with the addition of facilities and personnel. Before expansion, malaria investigations centered at a hospital of the United States Public Health Service in Bethesda; the Goldwater Memorial Hospital at New York University; the Rockefeller Institute; the Manhattan State Hospital and two hospitals for the mentally ill, St. Elizabeths Hospital, Washington, D.C., and the Gailor Psychiatric Hospital of the University of Tennessee. Joining the program in 1944 were the Boston Psychiatric Hospital of the Massachusetts General Hospital, the University of Chicago's state hospital 
for mental disease, the Psychiatric Division at Bellevue, the State Penitentiary in Atlanta, and Gorgas Hospital in the Canal Zone, where previously only Army scientists studied. ${ }^{10}$

In early 1944 military and civilian research became better integrated. In February, the Surgeon General assigned 12 Army physicians to civilian research centers investigating malaria. Army scientists worked at the University of Tennessee and the Rockefeller Institute's Princeton Branch. Civilian scientists worked alongside Army physicians at Gorgas. The Kennedy General Hospital in Memphis provided military patients for the University of Tennessee's malarial experiments, and the university gave immunological and parasitological research results and antigens (gallinaceum) to the Army. The civilian investigators had never had available the number of malaria patients that the Army had at Kennedy Hospital. Military and civilian scientists were becoming full research partners. ${ }^{11}$

The Army could focus on new drugs because field experience had proven the efficacy of atabrine for routine suppression and treatment. Troops fought on and occupied malarious islands without becoming malaria casualties. Malaria now became a serious problem only when troops became lax about taking the atabrine prophylaxis and wearing protective clothing. From the military point of view, the urgent and immediate aim of malaria research had been satisfied, and the attention of Army investigators could center on cooperation with civilian scientists in finding a cure. $^{12}$

During the first half of the war, civilian laboratories had tested more than 6000 new drugs on malaria parasites and sent the promising compounds to the panel on clinical testing for trial in man. From mid-war to June 1946, drug companies produced another 8000 new compounds for screening. The exchange of information through the Office of the Survey of Antimalarial Drugs, a central depot that catalogued and screened compounds and disseminated information to scientists investigating malaria, avoided duplication of effort on the various drugs tested. ${ }^{13}$

The clinical program focused on the hypothesis that an increase in the intensity of a suppressive antimalarial activity, of the type manifested by quinine and atabrine, would eventually result in a curative agent for vivax malaria. Scientists tried to increase progressively the antimalarial activity of groups of compounds, as evidenced by their ability to terminate a clinical attack. Their studies led to the extensive use of blood-induced infections in trials in New York, Boston, and Chicago on mental patients, and volunteer conscientious objectors or penitentiary inmates to determine absorption, excretion, and distribution of the new drugs in man. At 
the time of these trials, societal norms regarding the participation of mental patients in research had not been codified. Principles governing the protection of human subjects have subsequently been elaborated in the Helsinki Accords and the Belmont Report, and codified in the Code of Federal Regulations. The Board for the Coordination of Malarial Studies referred promising compounds to the clinicians of the Public Health Service and the armed forces for further investigation. The board also tried a second experimental approach, looking for curative agents that had different chemotherapeutic characteristics than either quinine or atabrine. ${ }^{14}$

The newer suppressive compounds belonged to a drug chain, named the 4-aminoquinolines, that were closely related to plasmochin (a tradename for pamaquine, a slightly toxic antimalarial). Scientists screened about 200 of these drugs for antimalarial activity in at least one avian infection and examined a smaller number for toxicity in at least one mammal. About ten of these drugs were tested in man. Two, SN-6911 and SN7618 , German synthetic drugs, received the most extensive research. SN6911 had been previously tested in Vichy Algeria and turned over to the board at the time of Algeria's liberation. SN-7618 had not been tested. A third promising drug, SN-8137, had less thorough exploration..$^{15}$

By the summer of 1944 , SN-6911, Bisulfate, had passed the usual investigative hurdles and undergone clinical testing in military and Public Health Service installations. The Army studied the drug at its Air Force School of Aviation Medicine, Randolph Field, Texas, and in India; the U.S. Navy experimented with SN-6911 at Klamath Falls Marine Base, Oregon, and at the Naval Medical Center in Bethesda; the Public Health Service did so at its Malaria Unit in Atlanta. Using board protocols, scientists conducted these tests at military installations on military patients with vivax malaria of south and southwest Pacific origin and in the Atlanta Penitentiary on prisoner volunteers with the same type of malaria. The teams compared the compound's antimalarial activity quantitatively with a standard antimalarial drug, such as quinine, atabrine, or plasmochin. The data indicated that $\mathrm{SN}-6911$ was as effective and no more toxic than atabrine while not staining the skin or causing gastrointestinal disturbances in ordinary therapeutic doses. ${ }^{16}$

The board sent the drug, a protocol, and data from toxicity studies of the compound through the Australian Military Mission to Brigadier Neil Hamilton Fairley, the director of medicine for the Australian Army Medical Corps and a noted malariologist. Fairley had recently reaffirmed the reliability of atabrine as a suppressant in trials at an Australian Army Malaria Research Unit in Cairns and at an Australian Army hospital on the Atherton Tableland in Queensland. Fairley used SN-6911 at the Cairns 
Army Base on mosquito-induced infections of vivax malaria in non-immune volunteers. His results matched those of the American investigators. He gave his report on the study to a member of the Board for the Coordination of Malarial Studies on a visit to New York in the autumn of 1944. ${ }^{17}$

Another promising suppressive antimalarial was SN-7618, later named chloroquine. After a long-term chronic toxicity study on volunteers at the Illinois Stateville Prison, SN-7618 received suppressive trials at two Army general hospitals-Moore in Swannanoa, North Carolina, and Harmon in Longview, Texas, where civilian scientists worked alongside Army investigators, and at Randolph Field, Texas. The Navy tried the compound at Klamath Falls Marine Barracks and at the Bethesda Medical Center. Brigadier Fairley examined SN-7618 at Cairns, and the International Health Division of the Rockefeller Foundation tested the drug on natives in Peru. Scientists compared the effectiveness, toxicity, and administrative advantages of weekly or biweekly dosages against the required daily dose of atabrine.

By the spring of 1945 , SN-7618 showed promise. The Army and Navy reported little toxicity and more rapid disappearance of fever and parasitemia than with atabrine. Furthermore, treatment of an acute attack with SN-7618 resulted in a longer period between relapses than with atabrine therapy. Fairley sent similar data from Australia and added that $\mathrm{SN}-7618$ suppressed and cured falciparum malaria as effectively as atabrine. The Peruvian study revealed that patients could safely receive SN-7618 in doses about twice those necessary for satisfactory suppressive action. In other investigations, most malaria cases had been on single weekly doses of 0.3 gram for 8 weeks. By that time medics were giving atabrine at 0.1 gram daily. The new compound was beginning to look better than atabrine. ${ }^{18}$

By the end of World War II, scientists agreed that SN-7618 was superior to atabrine. The administration of the drug once weekly in a well-tolerated dose brought effective suppression. It caused an abrupt termination of the clinical attack of vivax malaria after 24 hours to 48 hours as compared to the usual five-to-seven-day treatment with atabrine. It also cured falciparum malaria when given for only one or two days. Additionally, it did not stain the skin or produce gastrointestinal disturbances. Scientists could make similar claims for SN-6911 (Bisulfate) and SN8137 (Oxychloroquine). ${ }^{19}$ 


\section{Post-war Investigations}

After the Japanese surrendered in September 1945, the Army continued to investigate promising antimalarial drugs. They instituted clinical trials of SN-7618 in the Philippines, in India, and in stateside Army hospitals. The Army School of Malariology, activated in 1944 in the Canal Zone to provide field training under tropical conditions, tested SN8137 in endemic areas in rural Panama. The results were encouraging, but they had not produced a cure for vivax malaria. ${ }^{20}$

The U.S. Navy discovered in its trials of SN-6911, SN-11,437, SN7618, and SN-8137 at Camp Lejeune, North Carolina that all of the experimental compounds were less toxic than atabrine. Impressed with SN-6911, the Navy adopted the drug for routine use with the approval of the Board for the Coordination of Malarial Studies and its Clinical Panel in October 1945. With few patients available, the Navy anticipated no further trials in the United States. The Navy planned to compare the suppressive activity of SN-6911 with SN-7618 in experiments in Greece. By the end of 1945, the Naval Medical Research Unit in Bethesda had begun studies on the in vitro cultivation of malaria parasites in its search for a better antimalarial. ${ }^{21}$

Scientists studied another series of suppressive compounds, the quinolinementhanols that were closely related to quinine, in animals. But they never reached the stage of testing in people. Some new curative compounds in a series called the 8-aminoquinolines that were related to the British drug, pamaquine, received trial in prisons before the war ended, but not in armed forces' installations. Research teams developed a number of useful curative agents, but, as with SN-7618 and SN-8137 and associated compounds, did not exploit the full potentialities of these drugs. ${ }^{22}$

\section{The U.S.-Australian U.S.-Britain Relationships}

In their search for better antimalarials, U.S. scientists collaborated more with Brigadier Fairley of Australia than with other allied malariologists. The Americans respected the work of Fairley on atabrine suppression, which extended the earlier work of Dr. James Shannon of the Goldwater Memorial Hospital in New York, and led to more effective regimens of dosage. They were impressed with Fairley's comprehensive trials at the Australian Army Medical Research Unit in Cairns on more than 1000 nonimmune volunteers with blood-induced or mosquito-induced infections. America's National Research Council and Britain's 
Medical Research Council valued Fairley's investigative skills so much that they sent him known and potential antimalarial agents to try. ${ }^{23}$

The Australian Military Mission in Washington, D.C. was the main avenue of contact for the United States with the Australian malariologist. Colonel Ewen Downie of the Australian Army Medical Corps, who operated out of the military mission, sent Fairley board protocols, which Fairley rearranged to fit his style, copies of research summaries, armed forces' medical newsletters, and information on the program in the United States. Downie shared with the Americans the results of Australian research and, in one instance, recent strains of southwest Pacific vivax malaria for study in the United States. He corresponded with the Army surgeon general, Dr. Shannon, and other American scientists. As a result of Fairley's participation in the National Research Council studies, the Australians received more "in confidence" information on research in the United States than any other ally, including Britain. ${ }^{24}$

Although smaller and less organized than the American program and with fewer comprehensive trials than the Australian, the British effort was impressive. British scientists studied the clinical aspects of malaria at the National Institute for Medical Research in London, the Army Malaria Research Unit, Oxford, other university laboratories, the Royal Army Medical College, Millbank, and laboratories at Imperial Chemical Industries, Ltd. British Army forces conducted therapeutic trials in England, West Africa, and southeast Command, comparing quinine, atabrine (which the British called mepacrine), and plasmochin (which they called pamaquine). They concluded that plasmochin reduced relapse rates. In March 1943, the Malaria Research Council and Imperial Chemical Industries began a joint program to explore the possibilities of developing a more effective compound. At the same time, an exchange of information on antimalarial drugs between laboratories in Britain and the United States was established through the agencies of the British Medical Research Council and the U.S. Committee on Medical Research of the Office of Scientific Research and Development. ${ }^{25}$

Despite efforts at coordination, misunderstandings and delays characterized the U.S.-Britain relationship in malaria research. In 1943 the Americans had refused a British request for the use of St. Elizabeths Hospital in Washington, D.C. for clinical trials of antimalarials because of insufficient beds. In 1944 British scientists tried to borrow Dr. Shannon and Dr. Eli Marshall, chairman of the panel on pharmacology, for guidance and information on the program of malaria studies in the United States. Dr. George A. Carden, Jr., chairman of the Committee on Medical Research, refused because the committee could not spare the scientists. Ill 
will also resulted when the Americans did not share the British willingness to disclose information. The British Medical Research Council sent complete copies of the minutes of its malaria therapy subcommittee to the Board for the Coordination of Malarial Studies, but the Americans sent only synopses without the "in confidence" information. The sheer volume of investigations in this country, and the "in confidence" classification of many of the American compounds that had been patented or in which patent applications had been filed, inhibited the United States' ability to share data. In fact the "in confidence" label kept British scientists out of regular meetings of the United States malaria research committees and inhibited free discussion of interesting leads. So, few British scientists were invited to this country. Only members of the Board for the Coordination of Malarial Studies, its panels, and clinical investigators became privy to the "in confidence" information. Even American firms were not given the classified information of other companies in the United States held by the Survey Office. Selected groups in Britain and Brigadier Fairley of Australia received grams of potential antimalarials for testing but not information on methods of manufacture. The Americans requested that the composition of these drugs not be revealed to commercial firms. ${ }^{26}$

Allied scientists who received American manufactured drugs for testing were to be without commercial affiliations, in order to protect the trade secrets of the U.S. drug companies. Fairley tested the antimalarial paludrine for Imperial Chemical Industries; hence he was in contact with that firm. The Americans sent him new compounds anyway; they needed his expertise, and Australia did not manufacture drugs. However, J. H. Burn, the British liaison officer in medical research in America, who worked out of the British Central Scientific Mission in Washington, D.C., corresponded directly with British pharmaceutical firms without going through the malaria committee of the British Medical Research Council until the spring of 1945. This fact may have been unknown to the American scientific community at the time, although the Americans expressed concern to the British about a leak of classified material in the summer of 1944. It is not certain if any "in confidence" information had been made available to the British scientific liaison officer, and if such information had affected the state of drug research in England. The British may have felt justified in making use of "in confidence" material from the United States. In 1942, U.S. manufacturers had patented the production of penicillin, a British discovery, when Howard Florey, who helped produce the drug, appealed to American manufacturers because British companies seemed uninterested, and patenting medical research results for profit was then against ethical medical principles in England. As a result, British 
manufacturers had to pay U.S. royalties on the penicillin produced in Britain. The experience with penicillin changed the climate of official British opinion on the patenting of medical discoveries and inventions. ${ }^{27}$

Despite delays, misunderstandings, and lack of trust, overall the allies liberally provided guidance and exchanged studies. British scientists contributed to the numbered malaria reports issued by the Board for the Coordination of Malarial Studies between 1943 and 1946. They also routinely received these reports and meeting synopses. The medical departments of the British and American armies traded information on the effect of plasmochin on vivax relapses. But the close cooperation with Australia, particularly with Brigadier Fairley, was not duplicated with the British. ${ }^{28}$

The visit of Dr. Shannon and Dr. Robert Loeb, chairman of the Board for the Coordination of Malarial Studies, to England in March 1945 improved the climate and tools for reciprocity. The allies arranged for the exchange of information held "in confidence." They agreed that the inner group of the British Medical Research Council, the U.S. Board for the Coordination of Malarial Studies, and the U.S. Committee on Medical Research should become the repositories of all information. They also recognized that information classified "in confidence" in one country would be withheld from companies in the other. They finally allowed that the Board for the Coordination of Malarial Studies and the Medical Research Council could give general guidance concerning groups of compounds, but not specific information, to industrial concerns should overlaps become apparent, or should it prove advantageous to give general direction. ${ }^{29}$

\section{Collaboration Ends}

Collaboration in drug research ended with the closing down of the Board for the Coordination of Malarial Studies in June 1946. The contract between the Office of Scientific Research and Development and the National Academy of Sciences, for the maintenance of advisory committees and the funding of research, ended that month. Clinical scientists continued trials until mid-year, while the synthetic chemists, pharmacologists, and biologists concluded their programs under the board. The Committee on Medical Research declassified the numbered malaria reports, gave the National Institutes of Health the unused samples of antimalarials, and sent the pharmacological and clinical reports to the Food and Drug Administration. The U.S. Public Health Service received the files of the Office of the Survey and returned the cards of compounds held "in confidence" to the supplier. ${ }^{30}$ 
Before adjourning, the board suggested prompt publication of information on SN-7618 (chloroquine), which had proven superior to quinine and atabrine, in the Journal of the American Medical Association to acquaint the Veterans Administration with the compound. The board also advised the Veterans Administration on dosage schedules for therapy of returning troops using atabrine and chloroquine. On the board's recommendation, the Army adopted chloroquine as the standard drug for malaria suppression and treatment in October 1947. The board hoped that government and nongovernmental agencies and the military services would meet as a group in the post-war period to discuss problems of mutual interest. Unfortunately, the end of the war also ended for nearly two decades the impetus for a concerted coordinated attack on malaria. ${ }^{31}$

\section{Conclusion}

The World War II organization to fight malaria advanced our knowledge of the disease and our ability to control it. The National Research Council, the Board for the Coordination of Malarial Studies, the Office of Scientific Research and Development, Offices of the Surgeon General of the U.S. Army and the U.S. Navy, the Australian Military Mission, and the British Medical Research Council stimulated and coordinated research, disseminated information, and shared results. The 14,000 new drugs synthesized ( 8,000 after the establishment of the board) and the 734 malaria reports collected and distributed by the board attest to the productivity of war-stimulated research. Although the allies liberally provided guidance and freely exchanged studies, reciprocity with Great Britain suffered until the creation of a mechanism for safeguarding industrial secrets near the end of the war. Allied collaboration worked best with Brigadier Fairley of Australia whose comprehensive field trials stand out among the wartime program's achievements. Collaboration improved malaria therapy by the development of new drugs that proved superior to atabrine. Despite the failure to discover a cure, the armed forces, which had initiated collaboration, were satisfied with the results. Years of neglect in the advancement of antimalarial drugs had given way to favorable new compounds and better control of the disease. 


\section{Notes}

I wish to thank Frank Schubert and Robert J. T. Joy for their helpful comments and reviews of this article. The award of a Secretary of the Army Research and Study Fellowship from 1 October 1990 to 30 September 1991 aided me in preparing this work.

1. Statistics are from the Statistical and Accounting Branch, Office of the Adjutant General, "Army Battle Casualties and Nonbattle Deaths in World War II, Final Report 7 December 1941-31 December 1942," (June 1953), 93-95; Alan S. Walker, Clinical Problems of War (Canberra, Australian War Memorial, 1952), 96. Each allied service member who stayed in the southwest Pacific for one year had malaria four times.

2. Thomas A. Hart and William Hardenberg, "The Southwest Pacific Area" in Communicable Diseases, Malaria, "Medical Department, United States Army," ed. Ebbe Curtis Hoff subseries, Preventive Medicine in World War II (Washington, D.C.: Office of the Surgeon General, 1963), VI, 531, 579-80.

3. Gordon Harrison, Mosquitoes, Malaria and Man, A History of the Hostilities Since 1880 (New York: E.P. Dutton, 1978), 181, 183, 186.

4. Manuscript, "Malaria Reports" (Washington D.C.: Board for the Coordination of Malarial Studies, 1943-1946), 1, iii at the U.S. Army Center of Military History (hereafter cited as $\mathrm{CMH}$ ).

5. Ibid.

6. Letter, Dr. Lewis H. Weed to Maj. Gen. Norman T. Kirk, 21 October 1943 in Subcommittee on the Coordination of Malarial Studies, General 1943, MED: Malaria Studies, Records of the National Research Council at the National Academy of Sciences (hereafter cited as MED: Malaria Studies, NRC, NAS); "Malaria Reports," 1, vi, vii.

7. The panel on synthesis advised commercial drug companies on the production of new compounds with antimalarial activity; the panel on pharmacology advised laboratories on the testing of compounds in birds for estimations of the promise of antimalarial activity in man; the panel on clinical testing accepted drugs for preliminary testing in people in induced malaria, based on previous demonstrated toxicity and activity in animals; the panel on the biochemistry of antimalarials tried to uncover significant leads in the mechanism of action of parasite on host and of drug on parasite to guide the panel on synthesis into promising channels in the synthetic chemistry of antimalarials. "Malaria Reports," I, vi, vii.

8. Ibid., Minutes, 22 December 1943, Board for the Coordination of Malarial Studies, General 1943-1946, MED: Malaria Studies, NRC, NAS.

9. Ibid., "Malaria Reports," I, vi.

10. Memorandum, Weed to Dr. Alfred N. Richards, 1 February 1944, Board for the Coordination of Malarial Studies.

11. Ibid., Letter, Weed to Kirk, 14 September 1943, Board for the Coordination of Malarial Studies, Panels, Clinical Testing, Testing Centers, Gorgas Hospital, in MED: Malaria 
Studies, NRC-NAS. Letter, Francis R. Dieuaide to Robert Briggs Watson, 30 November 1943, RG 112, 710. Diseases, Malaria, National Records Center, Suitland, MD.

12. Statistics are from Hart and Hardenbergh, "The Southwest Pacific Area," 579.

13. "Malaria Reports," I, viii, ix; the Office of Scientific Research and Development contracted with Johns Hopkins University in July 1942 to create the Office of the Survey of Antimalarial Drugs.

14. Report, Shannon to the Board for the Coordination of Malarial Studies, 3 March 1945, Subject: Activities of the Investigative Units Responsible to the Panel for Clinical Testing of Antimalarial Agents, in MED: Malaria Studies, NRC, NAS. Code of Federal Regulations 45, Part 46.

15. $\mathrm{SN}$ is an abbreviation for the Latin secundum naturam, which means "according to nature."

16. Minutes, 31 May 1944; 4 August 1944; 28 December 1945, Board for the Coordination of Malarial Studies; Henry M. Thomas, "Southwest Pacific Area," in John Boyd Coates, Activities of Medical Consultants, "Medical Department United States Army," subseries, Internal Medicine in World War II (Washington, D.C.: Office of the Surgeon General, 1961), I, 739.

17. Letters, Shannon to Ewen Downie, 10 August 1944; Fairley to Downie, 25 September 1944; Carden to Downie, 6 November 1944; Loeb to Downie, 24 November 1944; Downie to Loeb, 27 November 1944. All of these are in Board for the Coordination of Malarial Studies, Panels, Clinical Testing, Testing Centers, Cairns Army Base Australia, MED: Malaria Studies, NRC, NAS; Mary Ellen Condon-Rall, "Allied Cooperation in Malaria Prevention and Control, The World War II Southwest Pacific Experience, Journal of the History of Medicine and Allied Sciences, 46 (October 1991), 506-09.

18. These two paragraphs are based on Letter, Carden to Loeb, 30 September 1944, in Board for the Coordination of Malarial Studies, Panels, Clinical Testing, Testing Centers, Cairns Army Base, Australia; Minutes, 2 May, 18 October 1944, Board for the Coordination of Malarial Studies; Minutes, 30 November 1945, Panel of Review; Report, Robert Briggs Watson and Carden to Committee on Medical Research and the Board for the Coordination of Malarial Studies, 20 August 1945, Subject: Current Status of a Field Study with SN-7618 in Peru, Board for the Coordination of Malarial Studies, Malaria Mission, Peru.

19. Shannon, "The Clinical Testing of Antimalarial Drugs," 712-16 in Advances in Military Medicine, ed., E.C. Andrus et al. (Boston: Little, Brown and Company, 1948); New York Times, 4 January 1946, Subject: "Wartime Research in Malaria," Board for the Coordination of Malarial Studies, Press Releases, 1944-1946, MED: Malaria Studies, NRC, NAS.

20. Letter, Roger Prentiss to Carden, 11 March 1946, Board for the Coordination of Malarial Studies, Panels, Clinical Testing, General 1943-1946; Minutes, 18 October 1945, 28 December 1945, 28 February 1946, 4 June 1946, Board for the Coordination of Malarial Studies; Minutes, 30 November 1945, Panel of Review. Luther S. West, "The South Atlantic and Caribbean Areas," 185-86, in Hoff, Communicable Diseases. 
21. Minutes, 28 December 1945, 28 February 1946, 4 June 1946, Board for the Coordination of Malarial Studies.

22. Shannon, "The Clinical Testing of Antimalarial Drugs," Advances in Military Medicine, ed. E.C. Andrus et al., the New York Times, 712-716; 4 Jan 1946, Subject: "Wartime Research in Malaria," Board for the Coordination of Malarial Studies, Press Releases, 1944-1946.

23. F.H.K. Green and Sir Gordon Covell, eds., Medical Research (London, Her Majesty's Stationery Office, 1953), 155-160.

24. See Letters, Robert F. Loeb to Ewen Downie, 22 September, 1944; Downie to Hamilton Fairley, 1 June, 22 September, 1944, all in 65/6/5, the Fairley Papers, Australian Academy of Science; Shannon to Downie, 10 August, 1944; George Carden to Downie, 6 November, 1944; Memorandum, Carden to Loeb and Shannon, 29 May, 1945, all in Board for the Coordination of Malarial Studies, Panels, Clinical Testing, Testing Centers, Cairns Army Base, Australia.

25. Green and Covell, Medical Research, 155-160.

26. Report, Shannon and Loeb to the Committee on Medical Research, 8 May 1945, Subject: Malaria Mission to England; Letter, Hamilton Southworth to George A. Carden, 8 August 1944, Board for the Coordination of Malarial Studies, Panels, Clinical Testing, Cairns Army Base, Australia.

27. Ibid., Letter, Sir Edward Mellanby to Dr. Frank Hawking, 28 November 1944; Memorandum, Sir Edward Mellanby, 2 February 1945. Both in File 3125A, Medical Research Council, London, England; Gwyn Macfarlane, Howard Florey. The Making of a Great Scientist (Oxford University Press, 1979), 360-70.

28. Letters, General Hugh J. Morgan to Major General A. G. Biggam, 5 May 1945, RG 112, 710. Diseases, Malaria; Biggam to Sir Edward Mellanby, 23 October 1943, 3125/A, Medical Research Council, London, England.

29. Report, Shannon and Loeb to the Committee on Medical Research, Subject: Malaria Mission to England," 8 May 1945; Minutes, 2 May 1945, Executive Session, Board for the Coordination of Malarial Studies.

30. Memorandum, Eli Kennerly Marshall, Jr. to Members of the Board, 4 September, 1945, Board for the Coordination of Malarial Studies, General, 1944-1946; Minutes, 28 February, 4 June, 1946, Board for the Coordination of Malarial Studies.

31. See "Chloroquine or SN 7618 (quinoline derivative) and activity of new antimalarial agent; statement approved by Board for the Coordination of Malarial Studies [R.F. Loeb and others]" JAMA 130 (April 20, 1946): 1069-1070. "The Bulletin of the U.S. Army Medical Department," 7 (October 1947): 834. 